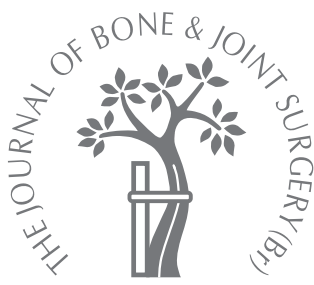

CASE REPORT

\title{
Dysplasia epiphysealis hemimelica with involvement of the hip and spine in a young girl
}

F. Haddad,

R. Chemali,

G. Maalouf

From Saint George

Hospital University

Medical Center,

Beirut, Lebanon
F. Haddad, MD, Orthopaedic Surgeon, Associate Professor R. Chemali, MD, Radiologist, Associate Professor

G. Maalouf, MD, Orthopaedic Surgeon, Professor

Saint George Hospital

University Medical Center,

Balamand University, Faculty of Medicine, P. O. Box 166378, Achrafieh, Beirut 11002807 .

Lebanon.

Correspondence should be sent to Professor F. Haddad; e-mail: fflhlb@yahoo.com

(C)2008 British Editorial Society of Bone and Joint Surgery doi:10.1302/0301-620X.90B7. $20784 \$ 2.00$

$J$ Bone Joint Surg $[\mathrm{Br}]$ 2008;90-B:952-6.

Received 21 January 2008;

Accepted after revision 3 March

2008

Dysplasia epiphysealis hemimelica of the left proximal femur was diagnosed in an eightmonth-old girl. At the age of $\mathbf{1 8}$ months, radiographs of the hip and MRI showed overgrowth and loss of containment of the femoral head. She underwent resection of the superior portion of the head and neck of the femur at the age of 2.5 years. Six months later further radiographs and an MR scan show that the mass has increased in size and that hip containment has been lost. Further plain radiographs have shown that the left knee, ankle and spine were involved.

To the authors' knowledge, this is the first report of dysplasia epiphysealis hemimelica involving both the lower limb and the spine. A review of the literature is presented.

Dysplasia epiphysealis hemimelica is an extremely rare developmental disorder of the skeleton which affects the epiphysis in young children. It is characterised by asymmetrical enlargement of one or more epiphyses of a joint, usually of the lower limbs, as a result of overgrowth of cartilage. Boys are affected three times as frequently as girls. In a recent review of the literature, we found only a few articles $^{1-9}$ describing a total of nine cases involving the hip, and only one report ${ }^{10}$ of involvement of the spine. We report what we believe to be the first published case of dysplasia epiphysealis hemimelica involving both the hip and the spine. The diagnosis and follow-up of the progressive hip deformity was carried out using plain radiographs and MRI.

\section{Case report}

The patient was the fourth child of healthy, non-consanguineous parents. The medical history of the family was unremarkable. Pregnancy had been uneventful and delivery occurred at full term of a baby of normal birthweight and length.

She initially presented elsewhere when aged eight months when radiographs (Fig. 1a) showed areas of accessory ossification around an enlarged left proximal femoral epiphysis. At the age of 18 months, radiographs (Fig. 1b) showed further enlargement of the epiphysis. An MR scan showed cartilaginous overgrowth of the femoral head and a CTguided biopsy showed the characteristic histological features of an osteochondroma.
She first presented to our institution when aged two years. There was gross limitation of movement of the left hip with particular limitation of rotation. Radiographs (Fig. 1c) showed the characteristic features of dysplasia epiphysealis hemimelica. She subsequently, six months later and again at another hospital, underwent resection of the superior aspect of the femoral head and neck. She is currently aged three years. There remains gross limitation of movement of the left hip and the left leg is $1.5 \mathrm{~cm}$ longer than the right. Radiographs (Fig. 1d) and MRI (Fig. 1e) show that the mass has increased in size and containment of the hip has been lost. Plain radiographs taken as part of a skeletal survey show that the left knee, left ankle and spine (Fig. 2) were also involved. A CT scan (Fig. 3) and MRI (Fig. 4) of the spine has been undertaken to provide additional detail. She has no symptoms other than a limp and so no further treatment is currently planned.

\section{Discussion}

Dysplasia epiphysealis hemimelica is a rare congenital disorder that affects one or more epiphyses, usually in the same limb. ${ }^{11}$ The condition was first described in 1926 by Mouchet and Belot as 'tarsomégalie'. ${ }^{12}$ It was defined by Trevor $^{13}$ in 1950 as a rare congenital growth disorder of the tarsus and of the epiphysis of the long bone; he reported eight cases of 'tarsoepiphyseal aclasis', and the condition became known as 'Trevor's disease'. In 1953, Ingelrans and Lacheretz' ${ }^{14}$ called it 'chondro- 


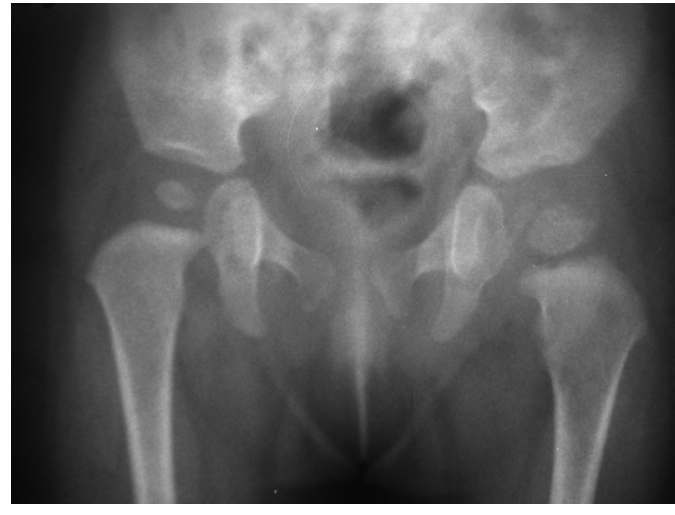

Fig. 1a

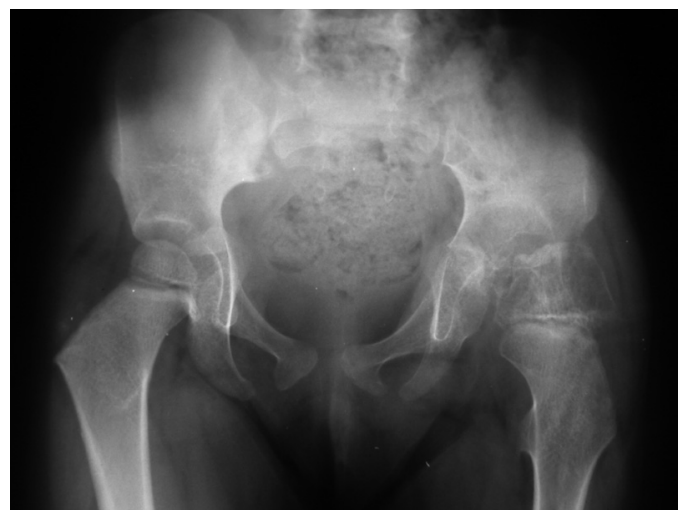

Fig. 1c

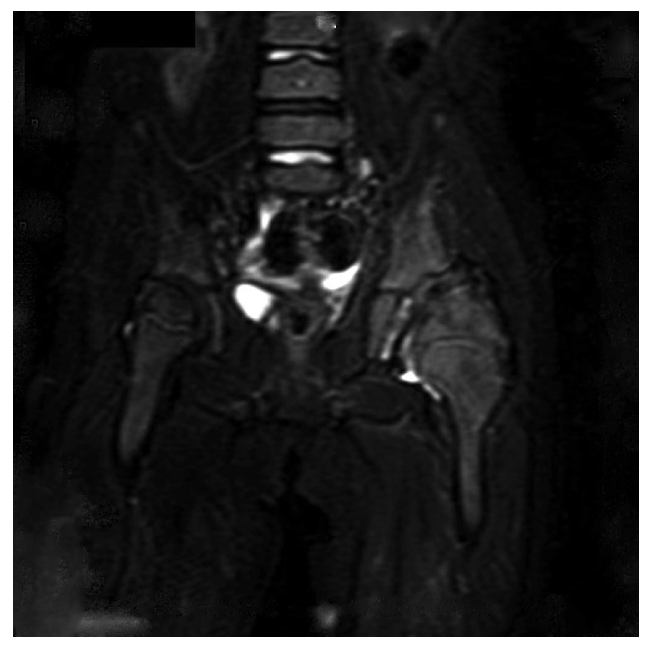

Fig. 1e

dystrophie épiphysaire', and in 1956 Fairbank $^{15}$ first used the currently accepted nomenclature dysplasia epiphysealis hemimelica in his report of 14 cases.

Most reported cases describe the involvement of several sites in a single lower limb. Azouz et $\mathrm{al}^{11}$ described different manifestations or patterns of involvement (localised, classic and generalised), depending on whether one, two or more joints of the same limb were affected. The most commonly

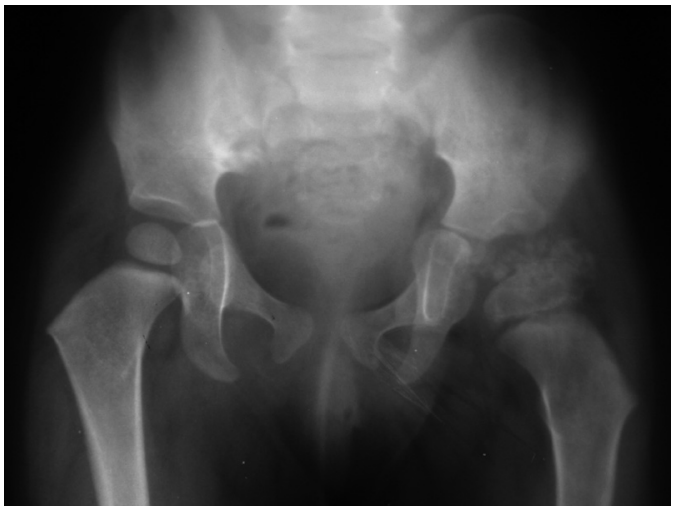

Fig. $1 \mathrm{~b}$

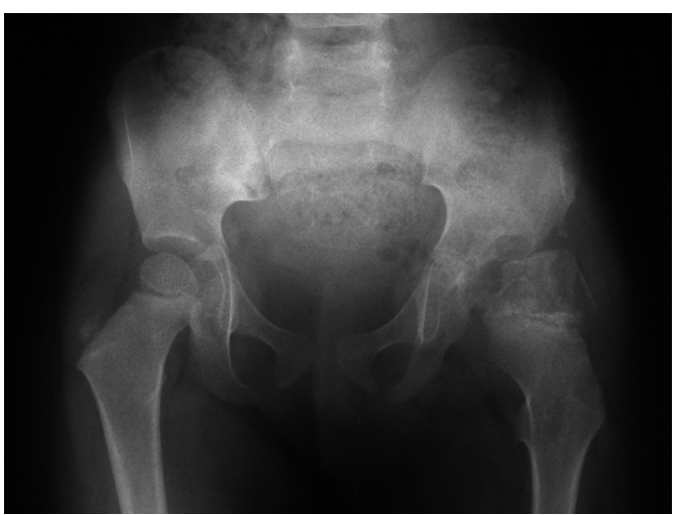

Fig. 1d

Anteroposterior radiographs of the pelvis a) at the age of 8 months, b) at the age of 18 months; an irregular calcified mass can be seen around the enlarged left proximal femoral epiphysis, c) at the age of two years; dysplasia epiphysealis hemimelica with an increase of calcification of the mass, d) at the age of three years; increasing size and ossification of the mass, and loss of containment of the hip, and e) MRI examination at the age of three years. involved sites are the hind-foot and ankle. ${ }^{7,11-17}$ The hip is rarely affected..$^{1-9}$ Although it is usually the lower limb that is involved, some authors ${ }^{18-21}$ have reported the condition in the upper limb. Schrot et $\mathrm{al}^{10}$ described one case involving the spine in a 15-year-old boy, in whom an osseous lesion compressed the C8 nerve root.

The reported incidence of dysplasia epiphysealis hemimelica is 1 in $1000000 .^{9,17}$ Most patients are first seen 


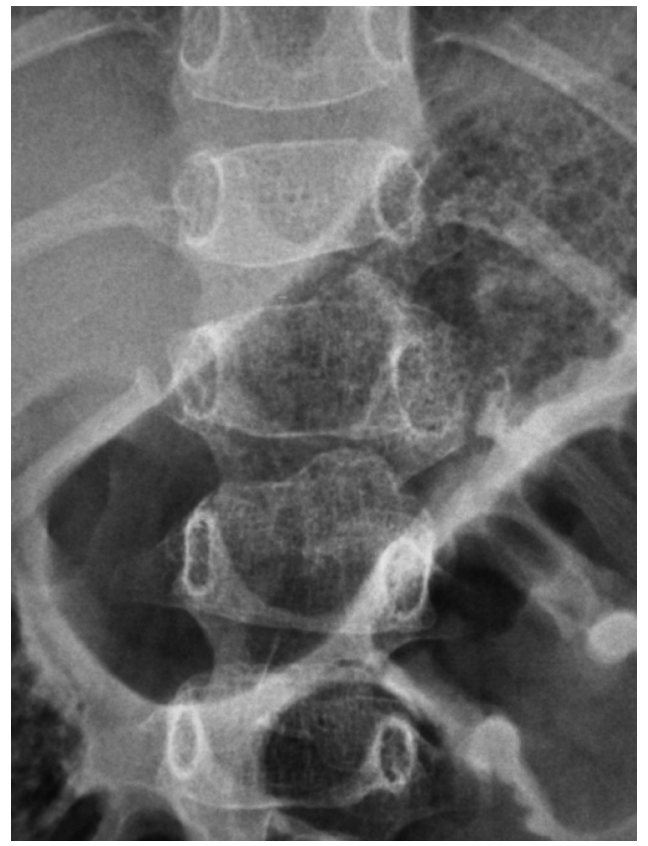

Fig. 2a

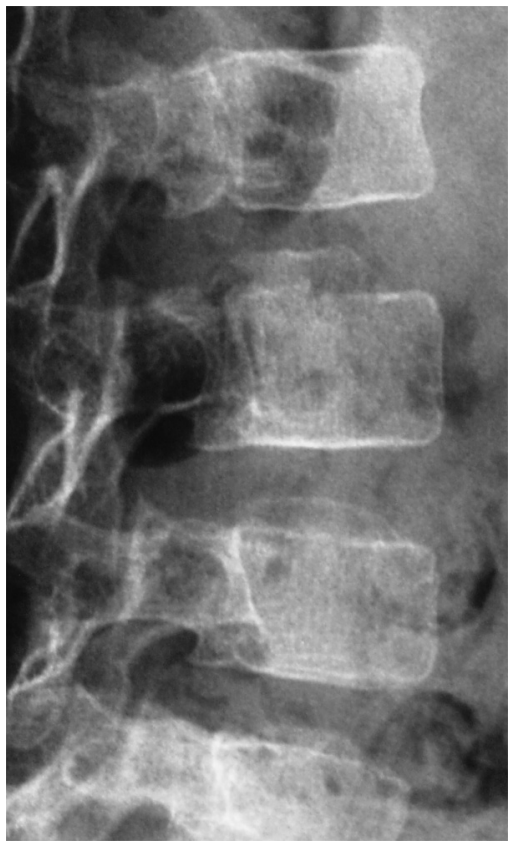

Fig. $2 b$

a) Anteroposterior and b) lateral radiographs of the spine, showing bony protuberances due to dysplasia epiphysealis hemimelica arising from the upper vertebral plateau.

between the ages of two and 14 years. $^{2,11,17}$ The condition occurs three times more commonly in boys than in girls. Its cause is unknown. Although there is no evidence of heritability, ${ }^{15,22}$ there is one report of a family being affected and the disorder being transmitted in an irregular dominant fashion. $^{23}$ The involvement of the affected epiphysis is hemimelic, meaning that either the medial or the lateral part of the centre of ossification is affected, the medial side more commonly. Cases of involvement of the entire epiphysis $^{3,15}$ and lesions involving opposite halves of different epiphyses in the same $\operatorname{limb}^{22}$ have been reported. In some cases both sides of the talus were involved, ${ }^{17}$ an exception to the laterality of the condition.

The epiphysis grows asymmetrically and forms an osteochondral protuberance that is macroscopically and histologically similar to an exostosis. This characteristic hemimelic pathological growth pattern results clinically in deformities, limb-length discrepancies, exostoses, and progressive loss of joint movement and congruency. Irregularity of the articular surface may lead to early secondary osteoarthritis. Some patients have presented with locking of the affected joint and have needed removal of a loose body. $^{17}$

Histologically the lesion is similar to an osteochondroma, but they are separate clinical entities distinguished by their different locations in bone. Osteochondromas arise from the metaphysis or diaphysis, whereas dysplasia epiphysealis hemimelica occurs in the epiphysis. The basic pathological process appears to be that of abnormal carti- lage proliferation with associated enchondral ossification of an epiphysis, or of a tarsal or carpal bone. A cleavage area of cartilage exists between the ossification centre of the pathological tissue and that of the epiphysis before they coalesce and eventually fuse. The natural history of dysplasia epiphysealis hemimelica is for the lesion to increase in size until skeletal maturity. Malignant transformation has not been reported. ${ }^{17}$

In most cases the diagnosis has been based on plain radiographs, ${ }^{11,13,15,16}$ which show the characteristic hemimelic pattern of asymmetrical epiphyseal overgrowth and exostoses of osteochondroma-like appearance. Typically, radiographs initially show an irregular mass with focal ossification arising from one side of the affected epiphysis. On maturation, the lesion ossifies and becomes confluent with the underlying bone. Premature closure of the physis may cause deformity or a limb-length inequality.

CT and arthrography have traditionally been used to define the anatomy of the involved regions, but MRI provides a much more accurate image $\mathrm{i}^{16,17,24,25}$ and can establish the diagnosis of dysplasia epiphysealis hemimelica at an early stage, perhaps before the onset of ossification. ${ }^{5}$ It shows the exact location and extent of the lesion, as well as any joint involvement or a potential plane of cleavage between the epiphysis and the pathological tissue. ${ }^{26}$ It may also show abnormalities of soft-tissue around the involved joints. ${ }^{25}$ It has a role in distinguishing dysplasia epiphysealis hemimelica from other entities, particularly tumours, ${ }^{26}$ 


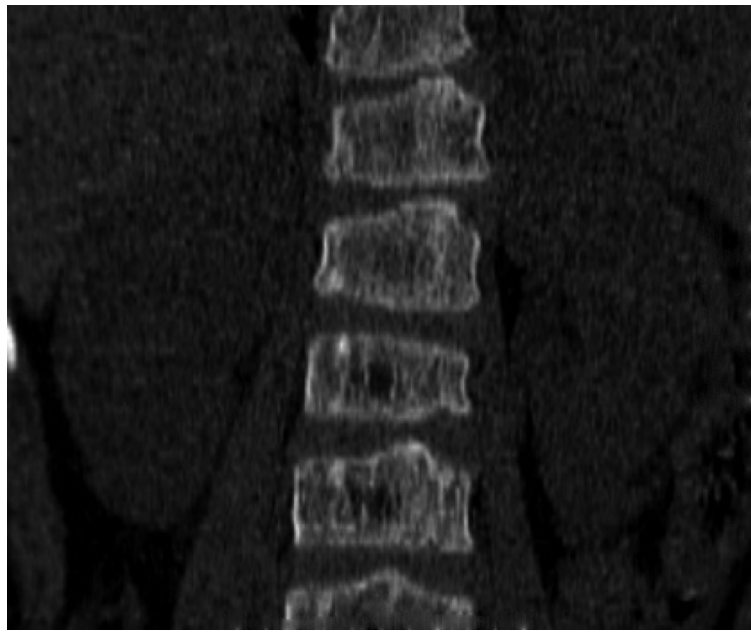

Fig. 3a

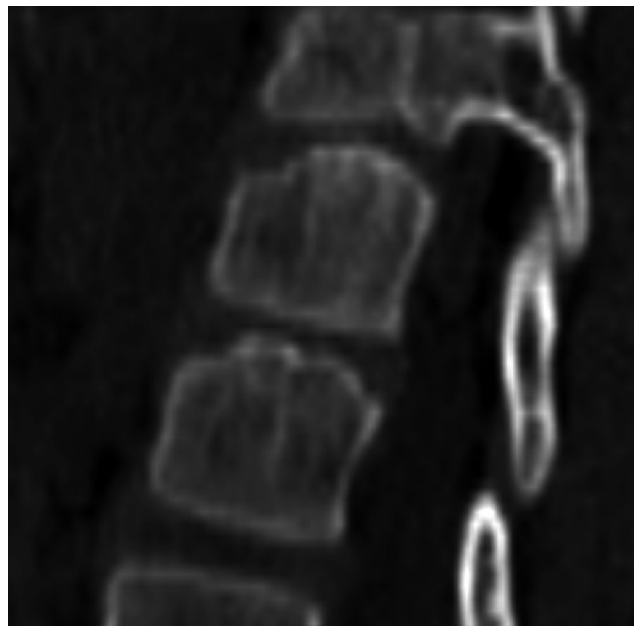

Fig. $3 b$

CT scan examination of the spine; a) coronal and b) sagittal reformatting showing the bony overgrowth arising from the upper vertebral plateau.

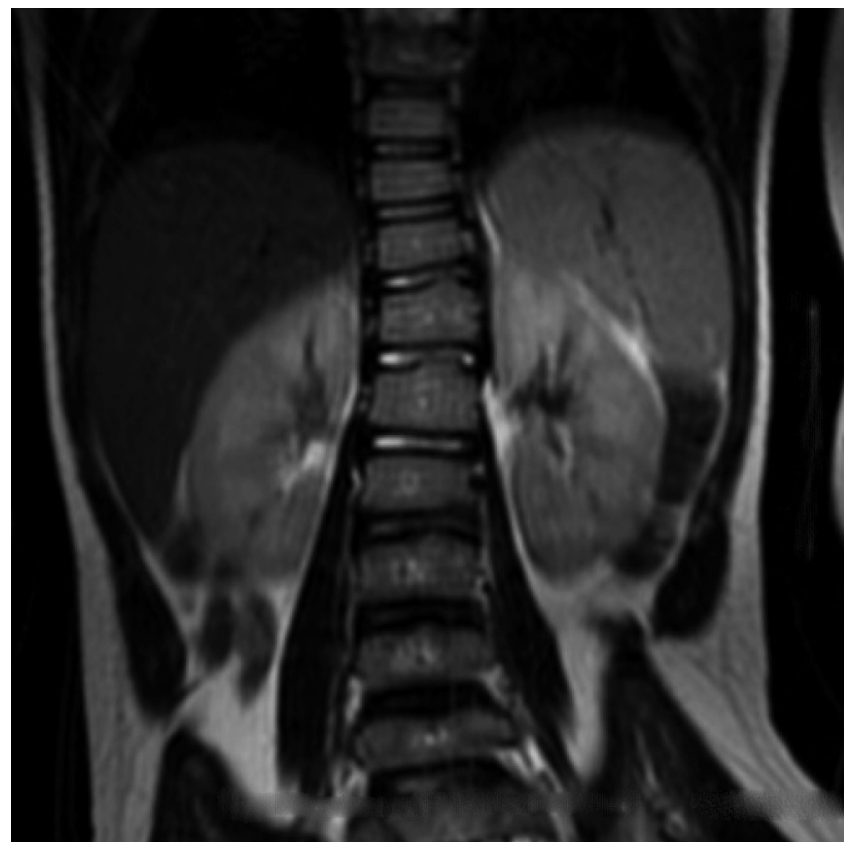

Fig. 4

MRI examination of the spine, showing the impression of the overgrowth on the lower end plate of the vertebra above.

and gadolinium enhancement may be useful in these cases. The use of MRI allows accutate non-invasive imaging of structural abnormalities of bone and cartilage and any secondary changes in tendons, ligaments and muscles. ${ }^{25}$ It can aid pre-operative planning and surgical treatment, and is helpful both in follow-up and in diagnosing recurrent disease. $^{7,27}$

Treatment ranges from simple observation to surgical excision. Asymptomatic lesions can be treated nonoperatively, as there is no known risk of malignant transformation. Surgery is only undertaken if the lesion causes pain, deformity or disability. ${ }^{17,27}$ Deformity can be treated by excision of the mass and a corrective osteotomy. ${ }^{16}$ Keret et $\mathrm{al}^{16}$ divided the lesions into intra- and extra-articular. If the mass is extra-articular, it may simply be excised. If it is intraarticular, excision is not recommended, but if the joint surface is smooth, any associated deformity can be corrected by an extra-articular osteotomy. The same authors warned of recurrence of the deformity if the growth plate of the affected joint was active, and when the disorder was around the knee and needed distal femoral osteotomy to be corrected. Kuo et al ${ }^{17}$ preferred to use the terms juxta-articular and articular, rather than extra- and intra-articular. The term extra-articular suggests that the lesion is extracapsular, but in their series they found that all cases had intracapsular epiphyseal lesions. They had excellent results with excision of juxta-articular lesions, but only fair or poor results with articular lesions, and did not recommend excision of an articular lesion unless it became a loose body. Arkader et al ${ }^{9}$ opted for a two-stage approach in a 14-year-old boy with an incongruent hip and insufficient acetabular cover. At the first stage they removed the intra-articular mass, then six months later carried out a modified shelf procedure for the residual hip dysplasia. Their management was successful.

To our knowledge, this is the first report of dysplasia epiphysealis hemimelica involving both the lower limb and the spine. Regular follow-up may allow early identification and presentation of a spinal deformity. We emphasise that early recognition and treatment of this rare condition is very 
important, and that MRI is of considerable assistance in its diagnosis and management.

No benefits in any form have been received or will be received from a commercial party related directly or indirectly to the subject of this article.

\section{References}

1. Bleshman MH, Levy RM. An unusual location of an esteochondroma. Radiology 1978;127:456.

2. Cruz-Conde R, Amaya S, Valdivia P, Hernández M, Calvo M. Dysplasia epiphysealis hemimelica. J Pediatr Orthop 1984;4:625-9.

3. Mendez AA, Keret D, MacEwen GD. Isolated dysplasia epiphysealis hemimelica of the hip joint: a case report. J Bone Joint Surg [Am] 1988;70-A:921-5.

4. Sherlock DA, Benson MK. Dysplasia epiphysialis hemimelica of the hip: a case report. Acta Orthop Scand 1986;57:173-5.

5. Skaggs DL, Moon CN, Kay RM, Peterson HA. Dysplasia epiphysealis hemimelica of the acetabulum: a report of two cases. J Bone Joint Surg [Am] 2000;82-A:409-14.

6. Woodward MN, Daly KE, Dodds RD, Fixsen JA. Subluxation of the hip joint in multiple hereditary osteochondromatosis: report of two cases. J Pediatr Orthop 1999;19:119-21.

7. Tschauner C, Roth-SchiffI E, Mayer U. Early loss of hip containment in a child with dysplasia epiphysealis hemimelica. Clin Orthop 2004;427:213-19.

8. Wenger DR, Adamczyk MJ. Evaluation, imaging, histology and operative treatment for dysplasia epiphysealis hemimelica (Trevor disease) of the acetabulum: a case report and review. lowa Orthop J 2005;25:60-5.

9. Arkader A, Friedman JE, Moroz L, Dormans JP. Acetabular dysplasia with hip subluxation in Trevor's disease of the hip. Clin Orthop 2007;457:247-52.

10. Schrot RJ, Kim KD, Fedor M. Trevor disease of the spine: case report. J Neurosurg Spine 2004;1:342-6.

11. Azouz EM, Slomic AM, Marton D, Rigault P, Finidori G. The variable manifestations of dysplasia epiphysealis hemimelica. Pediatr Radio/ 1985;15:44-9.

12. Mouchet A, Belot J. La Tarsomégalie. J Radiol Electrol Med Nucl 1926;10:289-93.
13. Trevor D. Tarso-epiphyseal aclasis: a congenital error of epiphysial development. $J$ Bone Joint Surg [Br] 1950;32-B:204-13

14. Ingelrans $\mathbf{P}$, Lacheretz $\mathbf{M}$. A propos d'un cas de chondrodystrophie épiphysaire. Rev Chir Orthop Réparatrice Appar Mot 1953;39:242-8 (in French).

15. Fairbank TJ. Dysplasia epiphysealis hemimelica (tarso-epiphyseal aclasis). J Bone Joint Surg [Br] 1956;38-B:237-57.

16. Keret D, Spatz DK, Caro PA, Mason DE. Dysplasia epiphysealis hemimelica: diagnosis and treatment. J Pediatr Orthop 1992;12:365-72.

17. Kuo RS, Bellemore MC, Monsell FP, Frawley K, Kozlowski K. Dysplasia epiphysealis hemimelica: clinical features and management. J Pediatr Orthop 1998;18:5438.

18. Azouz EM, Slomic AM, Archambault H. Upper extremity involvement in Trevor disease. J Can Assoc Radiol 1984;35:209-11.

19. Levi N, Ostgaard SE, Lund B. Dysplasia epiphysealis hemimelica (Trevor's disease) of the distal radius. Acta Orthop Belg 1998;64:104-6.

20. Hoeffel C, Hoeffel JC. Dysplasia epiphysealis hemimelica (Trevor's disease) of the distal radius. Acta Orthop Belg 1998;64:343-4.

21. Taniguchi Y, Tamaki T. Dysplasia epiphysealis hemimelica with carpal instability. J Hand Surg [Br] 1998;23:425-7.

22. Connor JM, Horan FT, Beighton P. Dysplasia epiphysealis hemimelica: a clinical and genetic study. J Bone Joint Surg [Br] 1983;65-B:350-4.

23. Fahmy MA, Pandey T. Epiphyseal osteochondromas with autosomal dominant inheritance and multiple parosteal bone proliferations. Skeletal Radiol 2008;37:6770.

24. Azouz EM. MRI of dysplasia epiphysealis hemimelica. Pediatr Radio/ 1996;26:904-9.

25. Peduto AJ, Frawley KJ, Bellemore MC, et al. MR imaging of dysplasia epiphysealis hemimelica: bony and soft-tissue abnormalities. AJR Am J Roentegenol 1999;172:819-23.

26. Lang IM, Azouz EM. MRI appearances of dysplasia epiphysealis hemimelica of the knee. Skeletal Radiol 1997;26:226-9.

27. Acquaviva A, Municchi G, Marconcini S, et al. Dysplasia epiphysealis hemimelica in a young girl: role of MRI in the diagnosis and follow-up. Joint Bone Spine 2005;72:183-6. 